\title{
Penerapan Model Personal Terintegrasi Distribusi Muatan dan Perencanaan Produksi
}

\author{
Sri Rahmayanti, Khairul Saleh, Hari Sumardi
}

(C) 2020 JEMS (Jurnal Edukasi Matematika dan Sains)

This is an open access article under the CC-BY-SA license (https://creativecommons.org/licenses/bysa/4.0/) ISSN 2337-9049 (print), ISSN 2502-4671 (online)

\begin{abstract}
Abstrak:
Perencanaan distribusi produksi terpadu dalam struktur rantai pasokan tertentu. Model Mixed Integer Linier Programming untuk meminimalkan kendala pengambilan keputusan dalam perencanaan produksi danmengirimkan produk tunggal kepada pelanggannya. Pengiriman dilakukan menggunakan armada kendaraan yang homogen. Pelanggan (pengecer) dikelompokkan di suatu wilayah sehingga jarak antara pengecer ini dapat diabaikan dibandingkan dengan jarak cluster dari pemasok. Tujuannya adalah untuk meminimalkan total biaya yang terdiri dari produksi, persediaan, dan biaya distribusi dengan lebih dari satu pemasok.
\end{abstract}

Kata Kunci: Model Personal Terintegrasi; Distribusi Muatan; Perencanaan Produksi.

\section{Pendahuluan}

Tujuan dari penelitian ini adalah untuk mengetahui kafasitas total biaya dan kendala stok dan total distribusi muatan dalam perencanaan produksi untuk lebih dari satu pemasok. Proses pengiriman dilakukan dengan menggunakan armada kendaraan yang homogen yang terdiri dari produksi, persediaan, dan biaya. Banyak perusahaan dalam menjalankan strategi bisnisnya yang mencoba mengoptimalkan produksi dan distribusi dengan sistem yang terpisah. Permasalahan ketidak sinkronan informasi antara departemen produksi dengan distribusi sangat berdampak pada total biaya yang di keluarkan perusahaan yang akan mengakibatkan menurunnya keuntungan.

Sri Rahmayanti, Universitas Asahan

yantiborunasti@gmail.com

Khairul Saleh, Universitas Asahan

khairulsibungsu@yahoo.com

Hari Sumardi, Universitas Bengkulu harisumardi@unib.ac.id 
Manajemen dan struktur rantai pasokan dibuat bertujuan untuk meminimalkan biaya operasi sambil memenuhi permintaan pelanggan dalam waktu yang singkat dan wajar.

Dalam perencanaan suatu rantai pasokan diperlukan koordinasi yang sinergis antara sebuah jaringan yang terdiri atas sumber daya pasokan, produksi dan distribusi. Perencanaan rantai pasokan merupakan interaksi antara pembeli dengan penjual yang melibatkan berbagai tahap yang dimulai dengan pasokan sampai dengan penjualan, Diantara pasokan dan penjualan terdapat perencanaan produksi dan distribusi produk.

Sebelum terdapat mata rantai pasokan, perencanaan produksi dapat dilihat sebagai perencanaan untuk memperoleh sumber daya dan bahan baku yang mengolah bahan baku menjadi produk dan pendistribusian hasil produksi. Perlu perhitungan yang komprehensif dan manajemen yang profesional dalam distribusi hasil produksi. Perencanaan rantai pasokan sangat bermanfaat untuk manejeral dalam menentukan aliran material bahan baku, pemasok, pusat distribusi, dan berakhir di pelanggan. Tujuan perencanaan untuk distribusi produk yang tepat ketempat yang sesuai dan pada waktu yang tepat untuk harga yang tepat (Xu et al., 2009 dan Yu et al., 2015). Penelitian ini dilakukan untuk menjawab permasalahan perencanaan produksi dan pendistribusian, khususnya multi produk utuk beberapa periode.

Salah satu masalah yang dapat diatasi dalam lingkup manajemen rantai pasokan adalah perencanaan produksi-distribusi yang merupakan kegiatan operasional yang melakukan rencana untuk proses produksi, untuk memberikan gambaran kepada manajemen seperti apa kuantitas bahan dan sumber daya lain- nya untuk mendapatkan total biaya operasi seminimal mungkin selama periode tersebut. Banyak model distribusi produksi dengan berbagai tingkat kesulitan telah diajukan dalam dekade terakhir untuk memecahkan masalah. Tahap pertama dalam memecahkan banyak masalah dalam ukuran dimana biaya routing diganti dengan perkiraan biaya distribusi tetap dan tahap kedua adalah fase routing. Hasil numerik menunjukkan bahwa ketidaksetaraan yang diusulkan tersebut memperbaiki kualitas solusi dan mengurangi waktu CPU pada kasus yang besar. Penelitian ini difokuskan pada perencanaan produksi mengetahui total biaya kafasitas dan kendala dalam perencanaan produksi dan disribusi muatan yang timbul dalam perindustri, yang menggunakan model mixe integer linier programming formulasi problem dalam perhitungan lebih dari satu pemasok.

Perumusan masalah dalam penelitian ini sama dengan yang disajikn di Y. Boutar-fa et al. (2016) dimana pencarian total minimum kapasitas biaya perencanaan produksi untuk persoalan distribusi muatan, biaya pengiriman, biaya penyimpanan dan perencanaan produksi lainnya menggunakan model Mixe Integer linier Programming yang menggunakan satu pemasok, maka dalam penelitian ini menghitung total minumun biaya kapasitas produksi dalam permintaan produksi yang menggunakan lebih dari satu pemasok

\section{Metode}

Metode penelitian ini dilakukan dengan studi literatur tentang distribusi muatan dan produksi. Dengan cara penentuan model untuk persoalan terintegrasi distribusi juatan dan 
perencanaan produksi dan melakukan kendala keputusan. Selanjutnya melakukan proses penerapan terhadap distribusi muatan dan perencanaan produksi dengan Model MILP.

Ditinjau dari penelitian sebelumnya, Beotarfa dkk. (2016), memberikan formulasi model untuk mixed integer linier programming formulation problem, dengan menggunakan model satu pemasok. Salah satu upaya untuk memperbaiki kinerja rantai pasok adalah dengan melakukan perencanaan produksi dan distribusi dengan seefisien mungkin Himpunan Indeks $\mathrm{T}=\{1, \ldots, \mathrm{T}\}$ himpunan periode

$\mathrm{J}=\{1, \ldots, \mathrm{J}\}$ himpunan pengecer

$\mathrm{K}=\{1, \ldots, \mathrm{K}\}$ himpunan angkutan

Indeks

$\mathrm{T}=1, \ldots, \mathrm{T}:$ periode waktu

$\mathrm{J}=1, \ldots, \mathrm{J}:$ pedagang

$\mathrm{K}=1, \ldots, \mathrm{K}:$ angkutan

Dari hasil penerapan MILP didapat perancangan model untuk memaksimalkan total keuntungan dalam multi-plant, multi-retailer, multi-item, multi-periode logistik.

Parameter

$\mathrm{d}_{\mathrm{jt}}$ : Permintaan pengecer $j$ pada periode $t$

${ }_{\mathrm{C}}^{\mathrm{C}}$ : Biaya pengiriman untuk pengecer $j$

W : Kapasitas setiap kendaraan

$\mathrm{S}^{\mathrm{P}}$ : Biaya produksi tetap

$\mathrm{h}^{\mathrm{P}}$ : Unit inventory holding fasilitas pemasok

$\mathrm{h}_{\mathrm{j}}^{\mathrm{C}}$ : Unit inventory holding cost untuk pengecer $j$

$\mathrm{I}_{\mathrm{j}}^{\max }$ : Kapasitas penyimpanan untuk pengecer $j$

$\mathrm{R}$ : biaya tetap penggunaan kendaraan

Q : kapasitas produksi pengecer

Variabel Keputusan

$y_{\mathrm{t}}$ : Variabel biner sama dengan 1 jika dan hanya jika kendaraan $k$ digunakan pada periode $t$

$\mathrm{q}_{\mathrm{t}}^{\mathrm{P}}$ : Kuantitas yang akan diproduksi pada periode $t$

$X_{j k t}$ : Variabel biner sama dengan 1 jika dan hanya jika pengecer $j$ dikunjungi oleh

kendaraan $k$ pada periode $t$

$I_{t}^{P}$ : Tingkat persediaan fasilitas pemasok pada periode $t$

$I_{j t}^{C}$ : Tingkat persediaan untuk pengecer $j$ pada periode $t$

$q_{j k t}^{C}$ : Kuantitas pengiriman ke pengecer $j$ menggunakan kendaraan $k$ pada periode $t$

$q_{k t}^{V}$ : Kuantitas pengiriman dengan menggunakan kendaraan $k$ pada periode $t$

$q l$ : Jumlah matriks yang dikirim dari $q l_{j} t$ pada elemen $q l$

$v_{k t}$ : Variabel biner sama dengan 1 jika kendaraan $k$ digunakan pada periode $t$

$$
\min \sum_{t=1}^{T}\left(S^{P} y_{t}+h^{P} I_{t}^{P}+\sum_{k=1}^{K} R v_{k t}+\sum_{j=1}^{j} \sum_{k=1}^{K} c_{j}^{C} x_{j k t}+\sum_{j=1}^{j} h_{j}^{C} I_{j}^{C}\right)
$$


Impelentasi Permasalahn dalam menghitung minimum total biaya produksi dari pengecer $j$ pada periode $i$ untuk meminimalkan biaya penyimpanan penyetok barang dari produksi ke pemasok $i$, dan jumlah dari total minimum biaya penggunaan kendaraan ke pengecer terhitung dari jumlah biaya distribusi pengantar ke $i$ dengan biaya penyimpanan dari pemasok.

Dilihat dari formulasi sebagai berikut :

$$
\min \sum_{t=1}^{T} \sum_{i=1}^{I}\left(S_{y_{t i}}^{P}+h_{i}^{P} I_{t i}^{P}+\sum_{k=1}^{K} R_{i} v_{k t i} \sum_{j=1}^{j} \sum_{k=1}^{K} c_{j}^{C} x_{j k t i}+\sum_{j=1}^{j} h_{i j}^{C} I_{j t i}^{C}\right)
$$

\section{Hasil dan Pembahasan}

Hasil pencarian model persoalan untuk meminimalkan total biaya yang dikeluarkan dari biaya pengaturan produksi, biaya penyimpanan persediaan untuk pemasok, biaya transportasi yang terdiri dari biaya tetap kendaraan dan biaya layanan, dan biaya penyimpanan persediaan untuk pengecer yang menggunakan lebih dari satu pemasok dengan langkahnya sebagai berikut untuk permasalah perencanaan terintegrasi muatan dengan memutuskan:

1. Minimum total biaya dari produksi ke pemasok 1

2. Minimum total biaya dari produksi ke pemasok 2 ke pengecer 1

3. Minimum total biaya dari pemasok 1 ke pengecer 2

4. Minimum total biaya dari pemasok 2 ke pengecer

Himpunan Indeks

$\mathrm{T}=\{1, \ldots, \mathrm{T}\}$ himpunan periode

$\mathrm{J}=\{1, \ldots, \mathrm{J}\}$ himpunan pengecer

$\mathrm{K}=\{1, \ldots, \mathrm{K}\}$ himpunan angkutan

$\mathrm{I}=\{1, \ldots, \mathrm{K}\}$ himpunan pemasok

Indeks

$\mathrm{t}=1, \ldots, \mathrm{T}:$ periode waktu

$\mathrm{j}=1, \ldots, \mathrm{J}$ : pedagang

$\mathrm{k}=1, \ldots, \mathrm{K}:$ angkutan

$\mathrm{i}=1,2, \ldots, \mathrm{I}$ : pemasok

Parameter

$d_{j t i}$ : Permintaan pengecer $j$ pada periode $t$ untuk produk dari pemasok ke- $i$

$c_{i}^{C} \quad$ : Biaya pengiriman untuk pengecer $j$ untuk produk dari pemasok $i$

$W \quad$ : Kapasitas setiap kendaraan

$S_{i}^{p} \quad$ : Biaya produksi tetap untuk barang dari pemasok $i$

$h_{i}^{P} \quad$ : Unit inventory holding fasilitas pemasok

$h_{j i}^{C} \quad$ : Unit inventory holding cost untuk pengecer $j$ dari pemasok $i$

$I_{j}^{\max }:$ Kapasitas penyimpanan untuk pengecer $j$

$R_{i} \quad$ : Biaya tetap penggunaan kendaraan untuk barang dari pemasok $i$

$Q_{i} \quad$ : Kapasitas produksi barang dari pemasok $i$ 
Variabel Keputusan

$y_{t} \quad$ : Variabel biner sama dengan 1 jika dan hanya jika kendaraan $k$ digunakan pada periode $\mathrm{t}$

$q_{t}^{p} \quad$ : Kuantitas yang akan diproduksi pada periode $t$

$x_{j k t i}:$ Variabel biner sama dengan 1 jika dan hanya jika pengecer $j$ dikunjungi oleh kendaraan $\mathrm{k}$ pada periode $\mathrm{t}$ ke pemasok $i$

$I_{t i}^{P} \quad$ : Tingkat persediaan fasilitas pemasok pada periode $\mathrm{t}$ ke pemasok $i$

$I_{j t i}^{C} \quad$ : Tingkat persediaan untuk pengecer $j$ menggunakan $\mathrm{k}$ pada periode $\mathrm{t}$ ke pemasok $i$

$q_{j k t i}^{C}:$ Kuantitas pengiriman ke pengecer $j$ menggunakan kendaraan $k$ pada periode $t$ ke pemasok $i$

$q_{k t i}^{V} \quad$ : Kuantitas pengiriman dengan menggunakan kendaraan $k$ pada periode $t$ ke pemasok $i$

$v_{k t i}$ : Variabel biner sama dengan 1 jika kendaraan $k$ digunakan pada periode $t$ ke pemasok $i$

Dalam menghitung minimum total biaya produksi dari pengecer $j$ pada periode $i$ untuk meminimalkan biaya penyimpanan penyetok barang dari produksi ke pemasok $i$, dan jumlah dari total minimum biaya penggunaan kendaraan ke pengecer terhitung dari jumlah biaya distribusi pengantar ke $i$ dengan biaya penyimpanan dari pemasok.

Dilihat dari formulasi sebagai berikut :

$\min \sum_{t=1}^{T} \sum_{i=1}^{I}\left(S_{y_{t i}}^{P}+h_{i}^{P} I_{t i}^{P}+\sum_{k=1}^{K} R_{i} v_{k t i} \sum_{j=1}^{j} \sum_{k=1}^{K} c_{j}^{C} x_{j k t i}+\sum_{j=1}^{j} h_{i j}^{C} I_{j t i}^{C}\right)$

Subject to

$$
\begin{array}{rcc}
I_{t}^{P}=I_{t-1}^{P}+q_{t i}^{P}-\sum_{j=1}^{J} \sum_{k=1}^{K} q_{j k t}^{C} & \forall t \in T \\
I_{j t}^{C}=I_{j t-1}^{C}-d_{j t}+\sum_{k=1}^{K} q_{j k t}^{C} & \forall j \in J & \forall t \in T \\
I_{j t}^{C} \leq I_{j i}^{m a x} & \forall j \in J & \forall t \in T \\
& q_{t}^{p} \leq Q_{y t} & \forall t \in T \\
\sum_{j=1}^{J} q_{j k t i}^{C} \leq W_{v k t} & , \forall k \in K & \forall t \in T \\
q_{j k t i}^{C} \leq W x_{j k t i} \quad \forall j \in J & \forall k \in K & \forall t \in T \\
\sum_{k=1}^{K} x_{j k t i} \leq 1 \quad j \in J & \forall t \in T & \\
q_{t}^{P}, I_{j, t, i}^{C} I_{t}^{P}, q_{j k t i}^{C} \geq 0 \quad \forall j \in J \quad \forall k \in K, \forall t \in T \\
y_{t}, x_{j k t}, v_{k t} \in\{0,1\} \quad \forall j \in J \quad \forall k \in K, \forall t \in T
\end{array}
$$

Fungsi objektif (4.11) meminimalkan total biaya yang dikeluarkan dari biaya pengaturan produksi ke pemasok $i$, biaya penyimpanan persediaan untuk pemasok, biaya transportasi yang terdiri dari biaya tetap kendaraan dan biaya layanan, dan biaya penyimpanan persediaan untuk pengecer. Kendala (4.12) kendala dalam periode waktu kapasitas penyimpanan, kwalitas yang akan dipenuhi dalam pengiriman ke pemasok 1 (4.13) adalah persamaan keseimbangan persediaan untuk pemasok 1 dan pengecer 1 . Kendala penyimpanan, produksi, dan kapasitas kendaraan ditunjukkan dari masing-masing pemasok ke pengecer oleh ketidaksetaraan. (4.14) kendala maximum tingkat persediaan untuk $j$ pada periode waktu ke pemasok 1 dalam ketidakseimbangan variabel biner kendaraan dalam pengiriman, (4.15) kendala persoalan kuantitas yang akan diproduksi pada periode waktu, (4.16) kendala total minimum kuantitas 
pengiriman ke pengecer dengan menggunakan kendaraan dalam periode waktu ke pemasok ke setiap kendaraan. Kendala (4.17) menghubungkan variabel qC yang kontinyu dengan variabel biner x. Kendala (4.18) memastikan bahwa pengecer dikunjungi paling banyak sekali dalam periode tertentu. Akhirnya, kendala (4.19) dan (4.20) adalah hambatan non-negativitas dan integralitas.

\section{Simpulan}

Dalam lingkaran persaingan saat ini, kemampuan bersaing suatu perusahaan tidak hanya ditntukan oleh kemapuan perusahaan itu sendiri tetapi tergantung pada jaringam operasi perusahaan itu. Maka dalam hal ini untuk memenuhi ke- butuhan pelanggan sangat dibutuhkan jaringan keterkaitan antara perusahaan membentuk suatu rantai pasokan. Produksi distribusi terpadu dalam rantai pasokan Model yang diusulkan terdiri dari lebih satu pemasok yang meren- canakan produksi dan pengirimannya ke pengecer terpencil yang dikelompokkan sedemikian rupa sehingga perhitungan jarak diabaikan dibandingkan dengan jarak cluster mereka dari pemasok. Hasil yang diperoleh menunjukkan bahwa pendekatan ini efisien untuk memecahkan masalah terpadu dan ukuran daftar Tabu adalah parameter penting yang memiliki dampak penting kinerja heuristik.

\section{Daftar Rujukan}

Adam, F. and Sammon, D. (2004). The Enterprise Resource Planning Decade: Lessons Learned and Issues for the Future. USA: Idea Group Publishing, Idea Group Inc.

Kallrath, J. (2005). Solving Planning and Design Problems in the Process In- dustry Using Mixed Integer and Global Optimization. Annals of Operations Research, Vol. 140, pp 339-373.

Mona, J., and Fitzsimmons. (2004). Service Management:Pperations, Strategy, and Information Technology. McGraw-Hill.

Newmann, K., Schwindt, C. and Trautmann, N. (2002). Advanced Production Scheduling for Batch Plants in Process Industries. OR Spektrum, Vol. 24, pp 251-279.

Or cun, S., Altinel, I. and Hortacsu, -O. (2001). General Continuous Time Models for Production Planning and Scheduling of Batch Processing Plants: Mixed Integer Linear Program Formulations and Computational Issues. Computers

\& Chemical Engineering, Vol. 25, 371-389.

Osvald, A. and Stirn, L. (2008). A vehicle routing algorithm for the distribution of fresh vegetables and similar perishable food. Journal of Food Engineering, Vol. 85(2), pp 285-295.

Pujawan, I. Nyoman, Supply Chain Management. Surabaya, Penerbit Guna Widya.

Russel, R.S. and B.W. Taylor. (2011). Operations Management: Creating Value Along The Supply Chain, seventh edition, John Wiley\&Sons.Inc. 
Soman, C.A., Van Donk, D.P. and Gaalman, G.J.C. (2004a). A basic period ap- proach to the economic lot scheduling problem with shelf life considerations. Int. J. of Prod. Res. Vol. 42, pp 1677-1689.

Soman, C.A., Van Donk, D.P. and Gaalman, G.J.C. (2004b). Combined make- to-order and make-to-stock in a food production system. Int. J. of Prod. Econ., Vol. 90, pp $223-235$.

Stevenson, J.W. (2009). Operation Management, eighth edition, McGraw-Hill. Yao, M. and Huang, J. (2005). Solving the economic lot scheduling problem with deteriorating items using genetic algorithms. Journal of Food Engineering, Vol. 70(3), pp 309-322.

You, E. and I. E. Grossman. (2009). Multi-echelon supply chain with invento- ry under uncertainty: MINLP models, computational strategies. AICHE Journal, Vol. 56, Issue 2, pp 419-440.

Y.Boutarfa, A. Senoussi, N. K. Mouss, N.Brahimi(2016). A Tabu Search Heuristic For an Integrated Oroduction- Distribution Problem With Clustred Retail- ers. IFAC, Vol.4912 , pp 1514-1519 